\title{
A STUDY ON PROPERTIES OF HIGH STRENGTH RECYCLED AGGREGATE CONCRETE WITH SYNTHETIC FIBRES
}

\author{
K.Jagannadha Rao ${ }^{1} \&$ M.V.S.S.Sastri ${ }^{2}$
}

Abstract Recycled concrete aggregates (RCA) are crushed, graded inorganic particles processed from the materials of concrete demolition debris. The aim of this research work is to study the behavior, in fresh and hardened states, of high strength structural concrete with recycled aggregates and synthetic fibres. The scope of this paper is to compare fresh and hardened state properties of high strength concrete by using various proportions of recycled coarse aggregates $(0,50 \%$ and $100 \%$ replacement of natural aggregates) along with $P P$ fibres $(0,0.2,0.3$ and $0.4 \%$ by volume of concrete). The parameters of investigation include tests on workability, compressive, flexural and indirect tensile strengths, and modulus of elasticity. It is observed that the workability of concrete considerably reduced with the increasing quantities of recycled aggregate and polypropylene fibres. The results showed a gradual decrease in compressive strength, tensile strength and secant modulus of elasticity as the percentage of recycled aggregate used in the concrete mix increased.

Keywords: High Strength Concrete, Recycled Concrete Aggregate, Polypropylene Fibres, Mechanical Properties.

\section{INTRODUCTION}

Providing shelter to its subjects is the fundamental duty of all governments which requires several materials such as concrete, steel, brick, stone and so on. However, the cement concrete remains the main construction material and for its suitability and adaptability concerning the changing environment. This widely used material must also be such that it can conserve resources, protect the environment, economize and lead to proper utilization of energy and major emphasis must be laid on the use of wastes and byproducts in cement and concrete. The utilization of recycled aggregate is particularly very promising as 75 percent of concrete is made of aggregates. In that case, the enormous quantities of demolished concrete are available at various construction sites, which are now posing a serious problem of disposal in densely populated urban areas. This can easily be done by recycling the aggregate. Research \& Development activities have been taken up all over the world for proving its feasibility, economic viability and cost-effectiveness.

The extensive research on Recycled Concrete Aggregate (RCA) has started from the year 1945 in various parts of the world after World War II but in a fragmented manner. The first effort has been made by Nixon (1978)[1] who compiled all the works on recycled aggregate carried out between 1945-1977 and prepared a state-of-the-art report while concluding that some researchers have examined the basic properties of concrete in which the aggregate is the product of crushing another concrete. A comprehensive state-of-the-art document on the recycled aggregate concrete has been presented by Hansen et al. (1986)[2] in which detailed analysis of data has been made, leading towards the preparation of guidelines for production and utilisation of RCA. RILEM technical committee 121-DRC[3] has given broad guidelines for the utilisation of RCA. Several

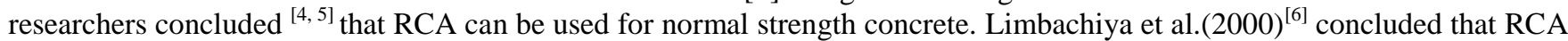
could also be utilised in high strength concrete and proper mix proportioning is the key to achieve strong and durable concrete. Though concrete lends itself to a variety of innovative designs, it suffers from several drawbacks that affect quality constructions such as Lack of toughness and ductility, Flexural strength limitation, Low abrasion/wear resistance, Inherent microcracks and Limited impact resistance.

To overcome above defects addition of Fibre to concrete is one of the solutions. Correct quantities and the right size of fibres when incorporated into conventional concrete substantially add to the strength when compared with concrete products made without fibre. FRC is also tougher and more resistant to impact in comparison with plain concrete. FRC conventionally uses steel fibre, and a lot of research work is being carried out on synthetic fibres also such as polyester, polypropylene. Synthetic fibre reinforced concrete (SNFRC) makes use of man-made fibres that are derived from organic polymers like acrylic, aramid, carbon, nylon, polyester, polythene and polypropylene fibres which have been tried as reinforcing material in Portland cement concrete. Since the use of PPFRC reduces water penetration and permeability by more than $50 \%$ with respect to control concrete, IS 2645 recommends it as waterproofing admixture. However, the basic attributes of PPFRC are a reduction in shrinkage cracks and improvement in elastic properties of concrete.

Dave and Desai(2007) ${ }^{[7]}$ found the addition of fibres produce non linear curve after first crack and reaches its peak at the ultimate strength of maximum sustainable static load and also the intricate matrix formed by huge number of fibres increase the compressive strength of a desired mix of concrete. Polymeric fibres having relatively low modulus of elasticity which

\footnotetext{
${ }^{1}$ Professor, Dept. of Civil Engineering, Chaitanya Bharathi Institute of Technology, Hyderabad, India.

${ }^{2}$ Asssociate Professor, Dept. of Civil Engineering, Vasavi College of Engineering, Hyderabad, India.
} 
reduce the initial stiffness and ultimate strength but their better extensibility results in an appreciable post-peak performance and toughness. Tam and Tam $(2008)^{[8]}$ developed a two-stage mixing approach to improve the quality of recycled coarse aggregate concrete for high-grade applications. The effects for the two-stage mixing approach can be attributed to the porous nature of recycled aggregate, and hence pores and cracks can be successfully filled up during the pre-mixing process, yielding denser concrete, improved interfacial zones around recycled aggregate and thus a higher strength in comparison with concrete using traditional mixing approaches.

Mukai et al. (1988) ${ }^{[9]}$ investigated the failure in low reinforced concrete beam specimens made with RCA and conventional aggregate concrete. The study also included the shear strength of low reinforced concrete of both the beams. The authors observed first cracking in RCA beam specimen. However, the ultimate load was similar in both the beams. Etxeberria et al. $(2007)^{[10]}$ produced four different recycled aggregates concretes made with $0 \%, 25 \%, 50 \%$ and $100 \%$ of recycled coarse aggregates, respectively. The authors concluded the utilization of RCA produced lower modulus of elasticity compared to conventional concretes and verified the numeral models proposed by several researchers. Tavakoli and Soroushian $(1996)^{[11]}$ carried out experimental work to determine the compressive, split tensile and flexure strength of recycled aggregate concrete and compared them with those of concrete made with the crushed natural aggregate. The authors concluded that the strength characteristics of recycled aggregate concrete are influenced by the strength of the original concrete, the ratio of coarse to fine aggregate in the original concrete, the ratio of the top size of aggregate in the original concrete to that of the recycled aggregate and the water absorption of recycled aggregate. Ajdukiewicz and Kliszcewicz $(2002)^{[12]}$ considered different grades of concrete ranging from M40 to M70 in their study and the recycled aggregate used was obtained from crushing concrete having a strength ranging from M40-M60.The results showed that the properties of original concrete significantly influence mechanical properties of recycled aggregate and it is possible to obtain recycled aggregate with higher strength than the original one. K.J.Rao(2011) ${ }^{[13]}$ conducted tests on concrete using glass/polyester fibres and Recycled aggregate and concluded that plain concrete beams with $0 \%$ RCA and 50\% RCA failed once the first crack was initiated, but the large deflections of fibrous concrete beams before failure indicated improved ductility.

In the present paper, an effort is made to compare some of the mechanical properties of high strength Recycled Aggregate Concrete (RAC) with the Natural Aggregate Concrete (NAC) using different percentages of PP 3S polypropylene fibres.

\section{MATERIALS USED AND EXPERIMENTAL METHODOLOGY}

Commercially available OPC 53 grade cement conforming to IS:12269 ${ }^{[14]}$ was used for preparing cement paste and concrete. The standard tests were conducted to find the characteristics of cement, and the results are tabulated in Table 1. Potable water available in the laboratory was used for the mixes.

Table1: Chemical composition and Physical properties of Cement

\begin{tabular}{|l|l|l|l|l|l|l|l|l|l|}
\hline $\begin{array}{l}\text { Chemical } \\
\text { composition }\end{array}$ & $\mathrm{CaO}$ & $\mathrm{SiO}_{2}$ & $\mathrm{Al}_{2} \mathrm{O}_{3}$ & $\mathrm{Fe}_{2} \mathrm{O}_{3}$ & $\mathrm{MgO}$ & $\mathrm{Na}_{2} \mathrm{O}$ & $\mathrm{K}_{2} \mathrm{O}$ & $\mathrm{SO}_{3}$ & $\mathrm{LOI}$ \\
\hline Value (\%) & 63.4 & 20.1 & 4.1 & 3.3 & 3.6 & 0.2 & 0.4 & 2.1 & 2.4 \\
\hline \multicolumn{10}{|l|}{} \\
\hline $\begin{array}{l}\text { Physical } \\
\text { properties }\end{array}$ & \multicolumn{1}{|l|}{ Blain fineness $\left(\mathrm{m}^{2} / \mathrm{kg}\right)$} & $\begin{array}{l}\text { Average primary particle } \\
\text { size }\end{array}$ & Specific gravity \\
\hline Value & 28.2 & 3.14 & \\
\hline
\end{tabular}

Fine Aggregate The local river sand passing through 4.75 I.S.Seive and retained on 150 micron was used for preparing the concrete. The sand is free from clayey matter, salt and organic impurities. The sand is tested for various properties like specific gravity, bulk density, etc., as per Grain size distribution of sand shows that it is close to the zone-III of IS:383 $3^{[15]}$

Natural coarse aggregate Crushed granite stone aggregate of nominal size passing $20 \mathrm{~mm}$ was used throughout the work.

Recycled concrete aggregate Field demolished concrete is used in the present study to produce the recycled aggregates. The concrete debris was collected with the age 7 to 10 years structure and broken into pieces of approximately $80 \mathrm{~mm}$ size with the help of hammer \& drilling machine. The foreign matters were sorted out from the pieces. Further, those pieces were crushed in a laboratory jaw crusher and sieved through a sieve of $4.75 \mathrm{~mm}$ to remove the finer particles.

Super plasticizer Polycarboxylic Ether based supplied by M/s FOSROC Chemicals India Private Limited was used.

Water Fresh potable water free from organic matter and oil was used for mixing of the concrete.

PP 3S Polypropylene Construction Fibres are triangular polyester fibre in cross section with cut length of $6 \mathrm{~mm} \& 12 \mathrm{~mm}$ which is being widely used in Indian construction industry. It is much cheaper than any other imported construction fibres. At the specified dosage of $0.25 \%$ by weight of cement, there are a million of fibres which form a mesh in concrete. The spacing is approximately less than $1 \mathrm{~mm}$ between any two fibre filaments in any coordinate of the matrix.

\section{EXPERIMENTAL INVESTIGATION}

The workability test includes slump and compaction factor and the hardened state properties like compressive, flexural and split tensile strengths, and static modulus of elasticity were conducted on standard test specimens in this investigation. 
Design Mix-ACI method of mix design was adopted and the grade of concrete is M60. The various ingredients and their quantities are shown in Table 2.

Table 2.Quantities of various ingredients of M-60 grade concrete

\begin{tabular}{|l|l|}
\hline Cement $\left(\mathrm{kg} / \mathrm{m}^{3}\right)$ & 594 \\
\hline Sand $\left(\mathrm{kg} / \mathrm{m}^{3}\right)$ & 596.75 \\
\hline Aggregate $\left(\mathrm{kg} / \mathrm{m}^{3}\right)$ & 1080 \\
\hline Water $(\mathrm{ltrs})$ & 185 \\
\hline Super plasticizer $\left(\mathrm{kg} / \mathrm{m}^{3}\right)$ & 5.5 \\
\hline 28Days Cube compressive strength $(\mathrm{MPa})$ & 68.75 \\
\hline
\end{tabular}

\section{TEST RESULTS AND DISCUSSIONS}

Results obtained from the experimental investigation are the mechanical properties of M-60 grade concrete with 0, 50 and 100\% RCA containing PP fibres. They are compared with the mechanical properties of plain concrete. The test results are shown graphically in the Figures 1 to 8 .

\subsection{Workability of concrete}

The slump test values of concrete grade M-60 with 0, 50 and 100\% RCA with different percentages of Recron 3S PP fibres viz, $0,0.2,0.3$ and $0.4 \%$ by weight of cement are shown in Fig 1. For normal aggregate the slump and compaction factor is satisfactory. From the results obtained, it is observed that there is no appreciable change in workability of conventional concrete and concrete with RCA and PP fibres. However, there is a marginal decrease in the workability as fibres were introduced.

\subsection{Compressive Strength}

Cube specimens were tested for compression, and the ultimate compressive strength was determined from failure load measured using the compression testing machine. The average values of the compressive strength of 3 specimens for each category at the ages of 7 and 28 days are shown in Fig 2. There is a marginal increase in compressive strength as the fibre content increased from 0 to $0.2 \%$ in natural aggregate concrete and there is a drop in the strength on further increase in fibre content. The same trend is observed even in recycled aggregate concrete upto a replacement of 50\% though there is a marginal decrease in strength of recycled aggregate concrete compared to natural aggregate concrete. However, there is a continuous reduction in strength when the natural aggregate is totally replaced by recycled aggregate for all percentages of fibres. The behavior is observed to be similar for seven days and 28 days properties.

\subsection{Split Tensile Strength}

Cylinder specimens were tested for splitting tensile strength. The test was carried out according to IS: 5816-1970. The variation in the splitting tensile strength of various concrete mixtures over plain concrete is also shown in Fig 3. The increase in Split Tensile strength of concrete with normal coarse aggregate (NCA) with $0.2 \%, 0.3 \%$ and $0.4 \%$ PP fibre was observed to be $17 \%, 4 \%$ and $13 \%$ respectively when compared to plain concrete. For concrete mix with $50 \%$ RCA, the increase in strength with the addition of PP fibres was observed to be $6 \%, 2 \%$ and $-4 \%$ respectively when compared to NCA concrete. For the grades of concrete M-60 with 0,50 and $100 \%$ RCA there is a maximum increase in the splitting tensile strength at $0.2 \%$ of fibre with the percentage increase $17 \%, 6 \%$ and $4 \%$ respectively. But when RCA completely replaced NCA at higher dosages of fibre, a decrease in strength of $12 \%$ was observed.

\subsection{Flexural Strength}

Prism specimens were tested under two-point loading at the age of 7 and 28 days and strengths are shown in Fig 4 . There is a marginal increase in strength of M-60 grade concrete with NCA and PP fibre of $0.2 \%, 0.3 \%$ and $0.4 \%$ when compared to plain concrete. Similar trend was observed for 50\% RCA also while for $100 \%$ RCA, a large reduction in flexural strength of about 26\% was observed for all PP fibre percentages owing to fibre balling and lesser strength of aggregate.

\subsection{Secant modulus of elasticity}

Concrete cylinders were tested for Secant modulus. The tests were carried out confirming to IS:516-1959. The variation in modulus of elasticity of various concrete mixtures over the plain concrete is shown in the Fig 5. The observed values are coinciding with observations made by several researchers around the globe.

\subsection{Ductility Characteristics}

The PP fibre induced prisms exhibited a little ductility characteristics with the appearance of crack before failure. At the failure load, a crack appeared in between the loading points and then specimens failed. It was also observed that with the 
percentage increase in the addition of PP fibre content from $0.0 \%-0.4 \%$, there was a decrease in deflections for the same load (Fig 6-8) indicating improved flexural stiffness of the beams.

\section{CONCLUSION}

The experimental results show that there is a slight decrease in workability with the use of recycled coarse aggregate and also with the addition of fibres. There is a marginal decrease in the strength of concrete as $50 \%$ of conventional coarse aggregate is replaced with recycled coarse aggregate. But in both these concretes (Natural aggregate and Recycled aggregate) the strengths were found to increase with the increase in fibre content up to $0.2 \%$ of PP $3 \mathrm{~S}$ fibre. It is observed that the strengths for concrete were continuously decreasing, even after adding the PP fibres, for concrete with $100 \%$ recycled aggregates. However, use of recycled aggregates upto $50 \%$ by weight of natural aggregates achieved required strength confirming the suitability of their use in high strength concrete of grade M60. The addition of polypropylene fibres improved the stiffness of the concrete while imparting ductility.

\section{ACKNOWLEDGEMENTS}

The present work is a part of UGC Minor Research Project No: F MRP 6242/15 (SERO/UGC) dated January 2015. The authors thank University Grants Commission for the financial help through the project. The authors express their sincere thanks to the management and administration of Chaitanya Bharathi Institute of Technology, Hyderabad for providing the laboratory facilities and administrative support.

\section{REFERENCES}

[1] Nixon, P., "Recycled concrete as an aggregate for concrete-a review," Materials and Structures, vol. 11, pp. 371-378, 1978

[2] Hansen, T. C., "Recycled aggregates and recycled aggregate concrete second state-of-the-art report developments 1945-1985," Materials and Structures, vol. 19 , pp. 201-246, 1986

[3] Materials and Structures, "121-DRG. guidance for demolition and reuse of concrete and masonry. Specifications for concrete with recycled aggregates," Recommendation, R.,

[4] Bairagi, N., Ravande, K., and Pareek, V., "Behaviour of concrete with different proportions of natural and recycled aggregates," Resources, Conservation and Recycling, vol. 9, pp. 109-126, 1993

[5] Bairagi, N., Vidyadhara, H., and Ravande, K., "Mix design procedure for recycled aggregate concrete," Construction and Building Materials, vol. 4, pp. 188-193, 1990

[6] Limbachiya, M., Leelawat, T., and Dhir, R., "Use of recycled concrete aggregate in high-strength concrete," Materials and Structures, vol. 33, pp. 574580,2000

[7] Dave, U. and Desai, Y., "Effects of polypropylene, polyester and glass fibres on various strengths of ordinary and standard concretes," 2007.

[8] Tam, V. W. Y. and Tam, C., "Diversifying two-stage mixing approach (TSMA) for recycled aggregate concrete: TSMAs and TSMAsc," Construction and Building Materials, vol. 22, pp. 2068-2077, 2008

[9] Mukai, T. and Kikuchi, M., "Properties of reinforced concrete beams containing recycled aggregate,Demolition and Reuse of Concrete and Masonry," Reuse of demolition waste,Proceedings of the Second International RILEM Symposium, Ed.Y.Kasai, vol. 2, pp. 670-679, 1988

[10] Etxeberria, M., Vázquez, E., Marí, A., and Barra, M., "Influence of amount of recycled coarse aggregates and production process on properties of recycled aggregate concrete," Cement and Concrete Research, vol. 37, pp. 735-742, 2007 https://doi.org/10.1016/j.cemconres.2007.02.002.

[11] Tavakoli, M. and Soroushian, P., "Strengths of recycled aggregate concrete made using field-demolished concrete as aggregate," ACI Materials Journal, vol. 93, pp. 182-90, 1996

[12] Ajdukiewicz, A. and Kliszczewicz, A., "Influence of recycled aggregates on mechanical properties of HS/HPC," Cement and Concrete Composites, vol. 24, pp. 269-279, 2002

[13] Rao, K. J., "Use of Recycled Aggregates in High Strength Fibrous Concrete for Sustainable Development," IUP Journal of Structural Engineering, vol. 4, 2011

[14] IS: 12269-2013, "Specification for ordinary Portland cement, 53 grade (first revision)," BureauofIndianStandards,New Delhi, India.

[15] IS: 383-1970:(reaffirmed 2011), "Specification for coarse and fine aggregates from natural sources for concrete(second revison)," BureuofIndianStandards, New Delhi, India.

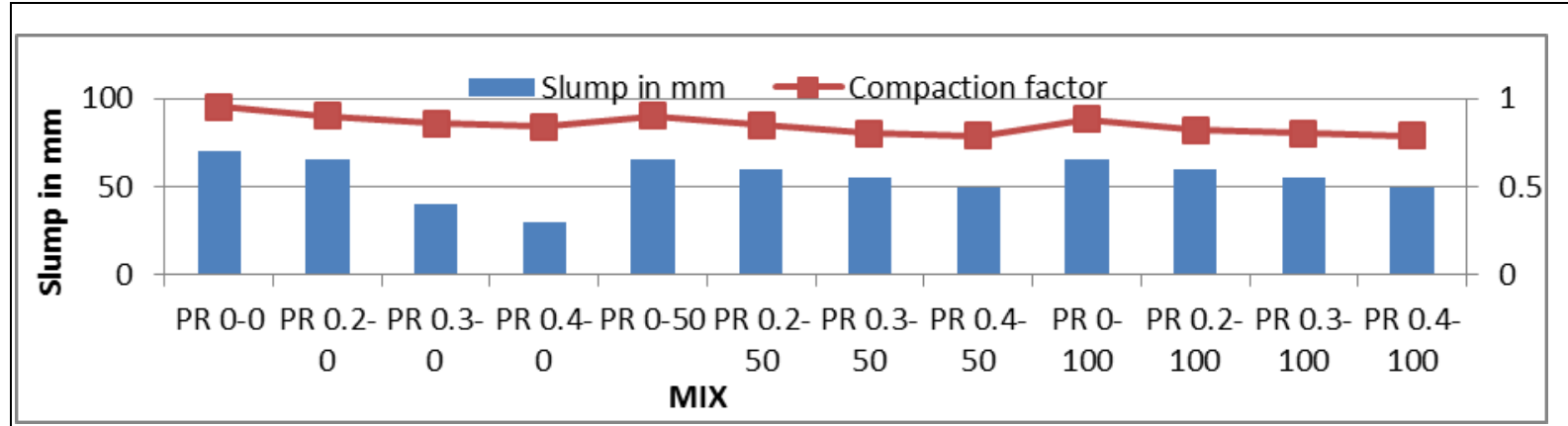

Fig 1. Variation of Slump and compaction factor with different fibre and RCA content 

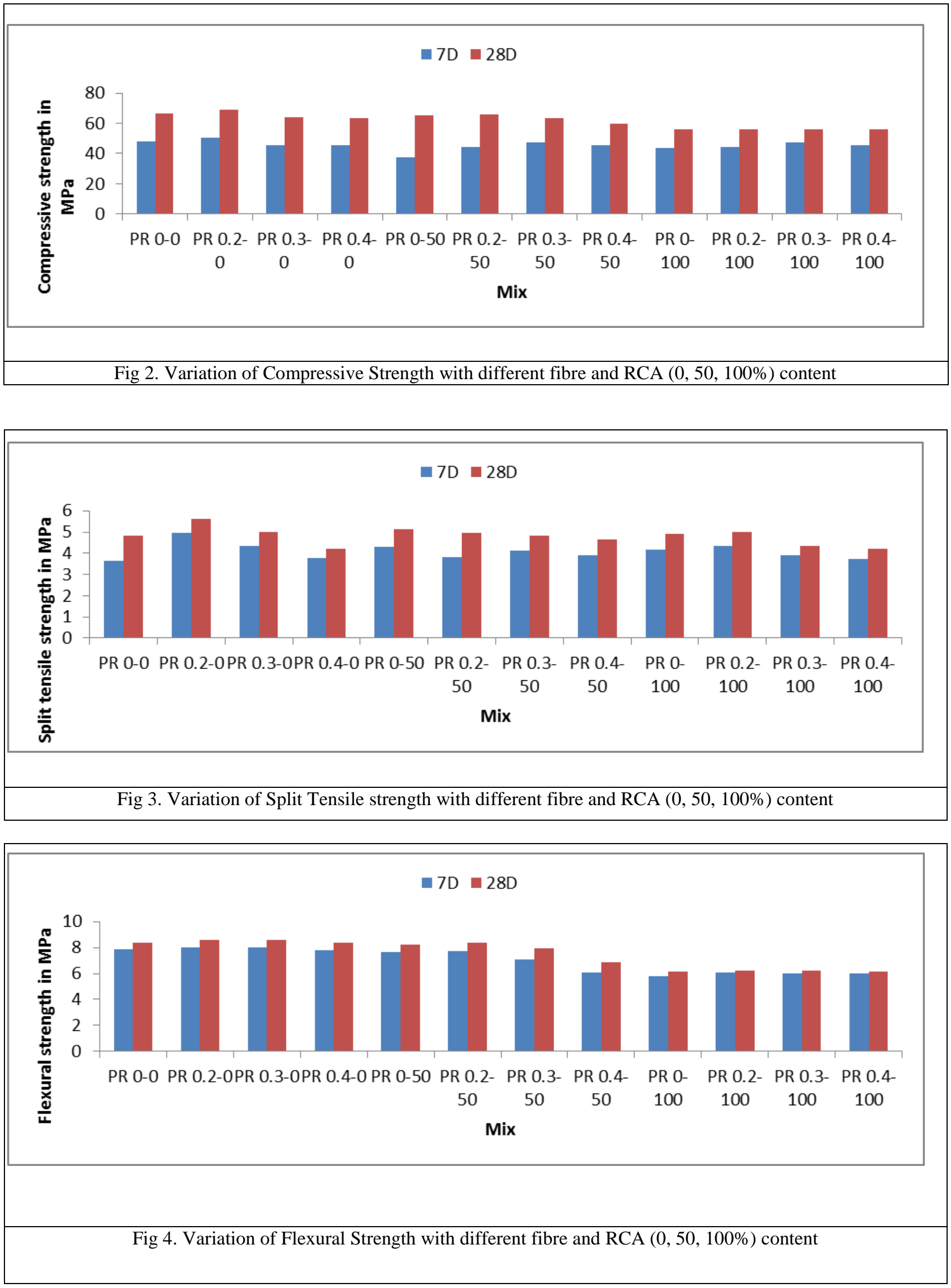

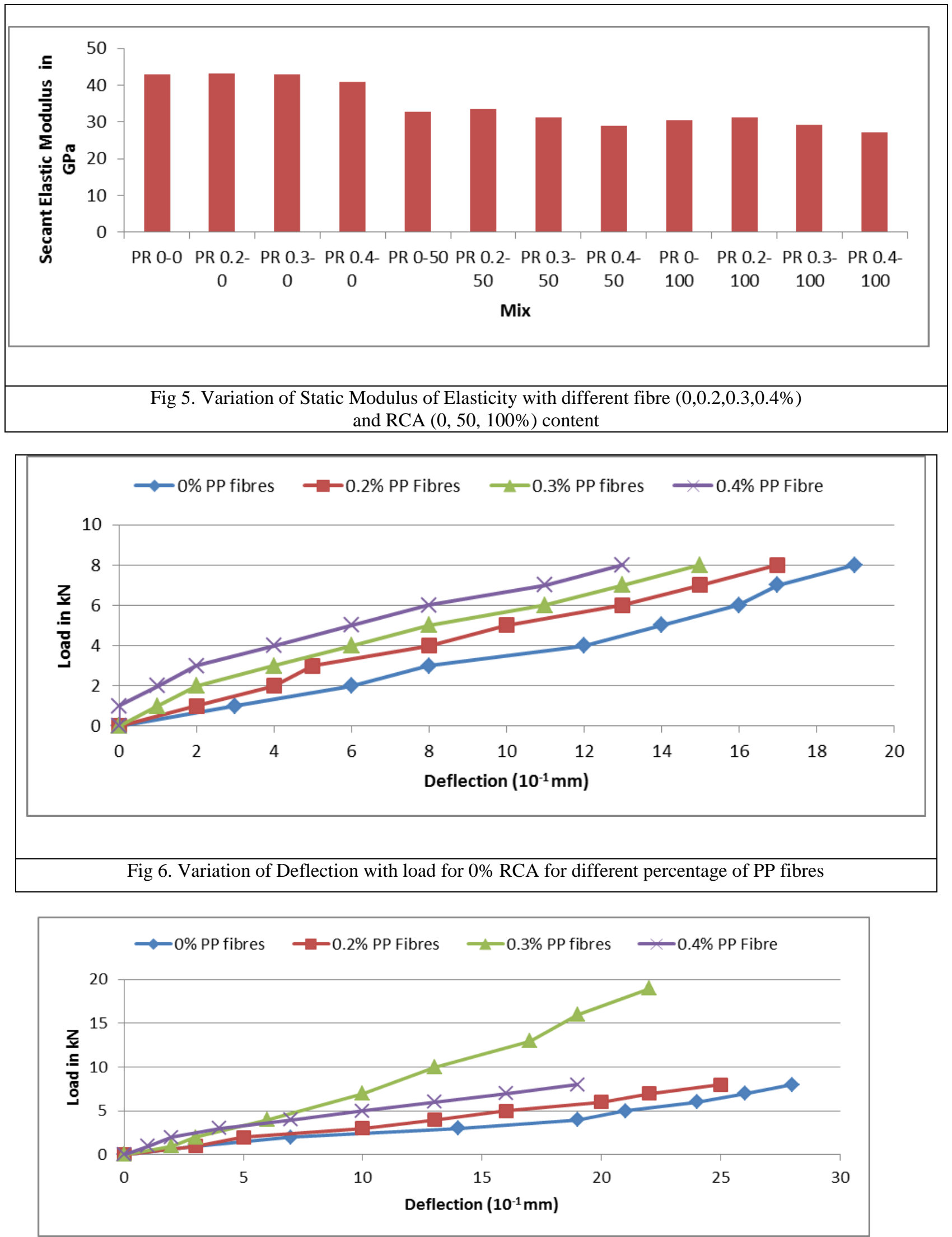

Fig 7. Variation of Deflection with load for 50\% RCA for different percentage of PP fibres 


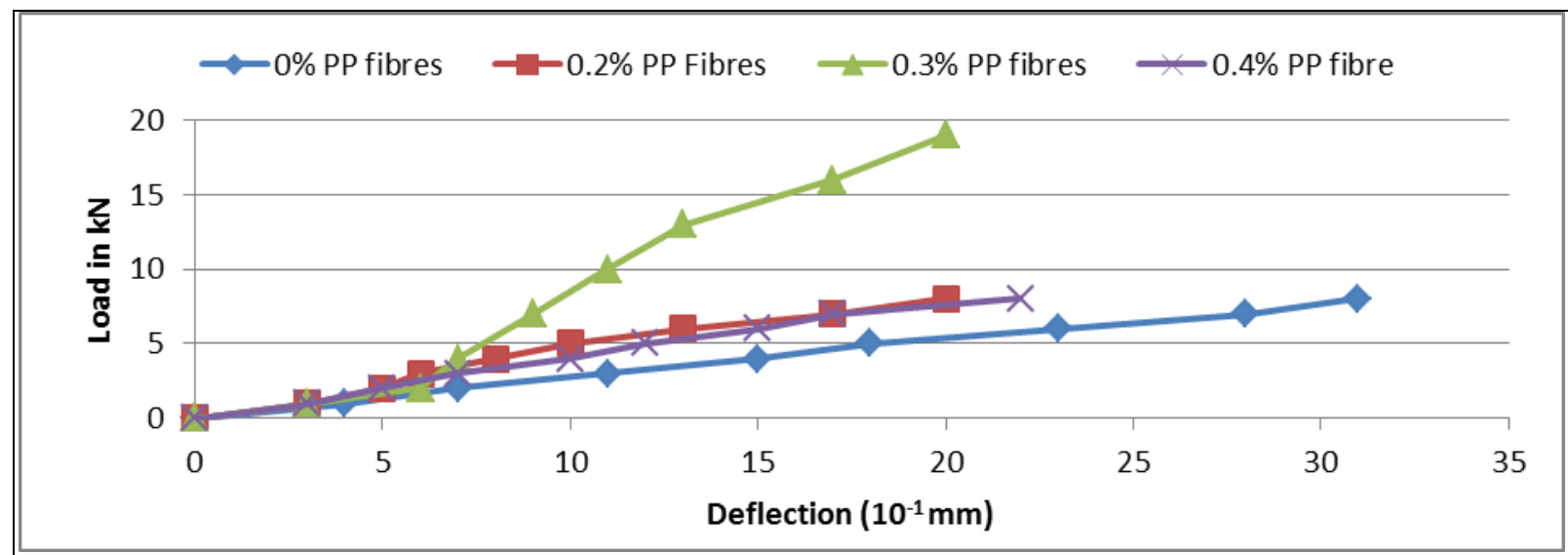

Fig 8. Variation of Deflection with load for $100 \%$ RCA for different percentage of PP fibres
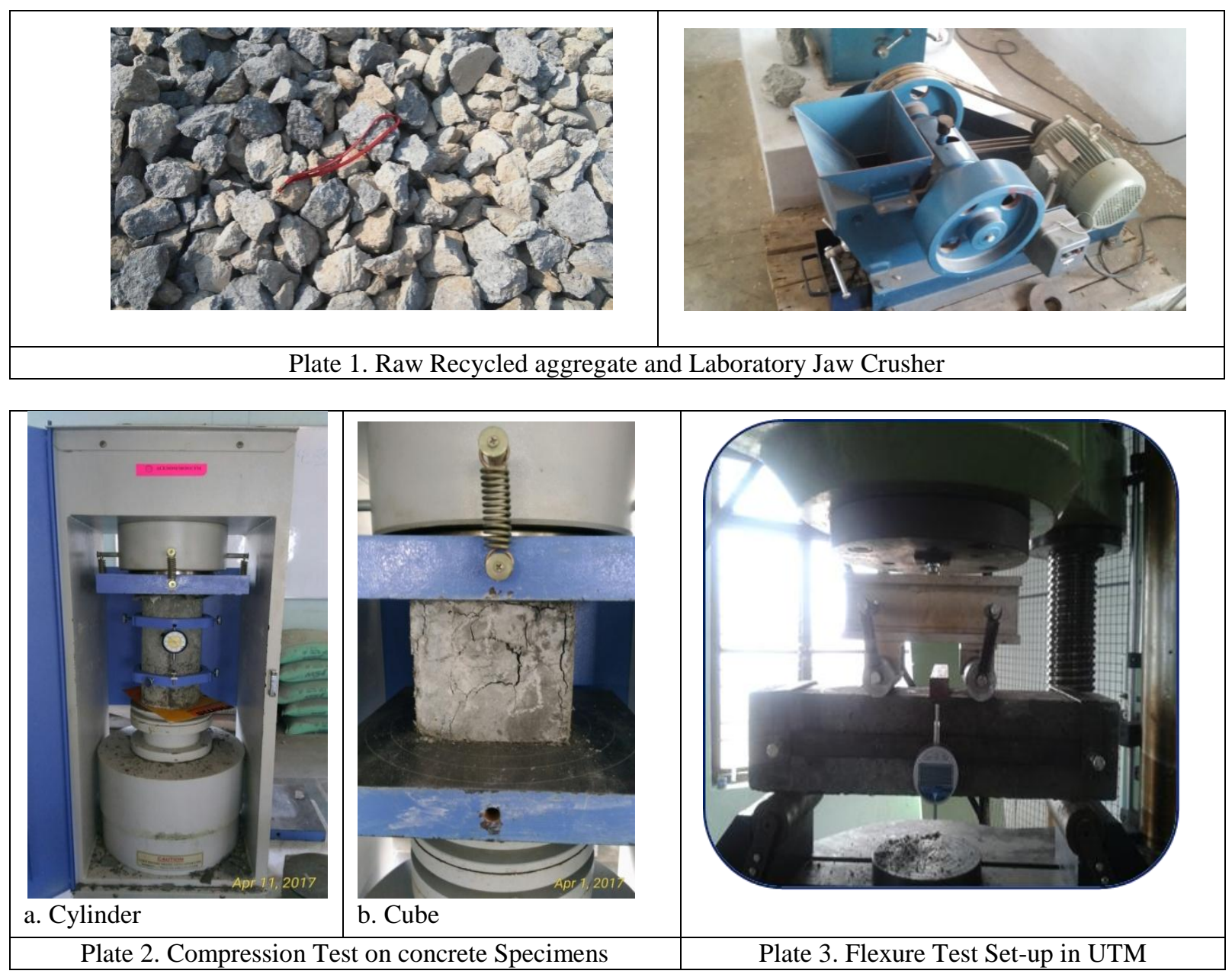